\title{
Correction to: Effects of acute pain and strain of the periodontium due to orthodontic separation on the occlusal tactile acuity of healthy individuals
}

\author{
Rosaria Bucci ${ }^{1} \cdot$ Michail Koutris $^{2} \cdot$ Vittorio Simeon ${ }^{3} \cdot$ Frank Lobbezoo $^{2} \cdot$ Ambrosina Michelotti $^{1}$ \\ Published online: 28 September 2021 \\ ๑) Springer-Verlag GmbH Germany, part of Springer Nature 2021
}

Correction to: Clinical Oral Investigations

https://doi.org/10.1007/s00784-021-03971-z

The names of the authors in the original version of this article were inversed.

The original article has been corrected.

Publisher's note Springer Nature remains neutral with regard to jurisdictional claims in published maps and institutional affiliations.

The original article can be found online at https://doi.org/10.1007/ s00784-021-03971-z.

\section{Rosaria Bucci}

rosaria.bucci@unina.it

1 Department of Neurosciences, Reproductive Sciences and Oral Sciences, School of Orthodontics and Temporomandibular Disorder, University of Naples Federico II, Via Pansini 5, 80131 Naples, Italy

2 Department of Oral Kinesiology, Academic Centre for Dentistry Amsterdam (ACTA), MOVE Research Institute Amsterdam, University of Amsterdam and VU University Amsterdam, Amsterdam, The Netherlands

3 Department of Public, Clinical and Preventive Medicine, Medical Statistics Unit, University of Campania 'Luigi Vanvitelli', Naples, Italy 